\title{
On Optical Mark-Sense Scanning
}

\author{
Douglas W. Jones ${ }^{\star}$ \\ University of Iowa, Iowa City IA 52242, USA
}

\begin{abstract}
Optical mark-sense scanning has lead to a resurgence in the use of paper ballots in the United States, despite a century of strong competition from paperless direct-recording voting systems. By the time mark-sense technology emerged, procedural measures had been developed to counter most of the vulnerabilities of paper ballots. Automatic counting of paper ballots poses technical and legal problems, but by counting the paper ballots automatically in the presence of the voter, mark-sense systems address some of the remaining problems with paper ballots. The best current technology uses precinct-count optical scanners to capture pixelized images of each ballot and then process the marks on that image. While this technology may be among the best voting technologies available today for the conduct of complex general elections, it faces one significant problem, access to voters with disabilities. There are promising solutions to this problem, but work remains to be done.
\end{abstract}

\section{Paper Ballots}

Considerable effort has gone into developing paperless voting systems over the past century, but paper ballots have proven to be a remarkably durable voting technology. Mechanical voting machines, first used in the 1890s [16], promised to eliminate the paper ballot. By the 1960's, when Joseph Harris introduced the Votomatic punched-card voting system [30], mechanical voting machines had displaced paper throughout most of the United States.

Several mark-sense scanning systems were introduced at about the same time that could directly read and tabulate marks made on paper ballots. Between these systems, paper ballots made a strong comeback in the last three decades of the 20th century. By 1988, machine-counted paper ballots were being used by almost half of the electorate in the United States, while mechanical voting machines were used by about one third [41].

The second technology to challenge paper ballots was the direct-recording electronic voting machine. While there is one 19th century antecedent for this technology [45], the first successful application of this idea was the Video-Voter, patented in 1974 [37]. By 1988, this new technology had only very limited market penetration, but by 2004 , almost one third of the electorate in the

\footnotetext{
* This material is based upon work supported by the National Science Foundation under Grant No. CNS-052431 (ACCURATE). Any opinions, findings, and conclusions or recommendations expressed in this material are those of the author and do not necessarily reflect the views of the National Science Foundation.
}

D. Chaum et al. (Eds.): Towards Trustworthy Elections, LNCS 6000, pp. 175-190, 2010.

(c) IAVOSS/Springer-Verlag Berlin Heidelberg 2010 
United States was using direct-recording electronic voting machines, while an equal number were using optical mark-sense machinery [23]. By this point in time, hand-counting, mechanical voting machines and punched cards were all in retreat.

\section{The Decline and Re-emergence of Paper}

The decline in hand-counted paper ballot use in the United States followed from two distinct causes. The first is the perception that was very widespread a century ago that mechanized vote tabulation was inherently more resistant to fraud than hand-counted paper ballots. This position is very evident in several important reports from the 1920s and 1930s, such as [46] and [29] (see pages 370 to 375$)$.

The second reason for the decline of hand-counting is the complexity of general elections in the United States. Where much of the world puts only one contest on the ballot, general election ballots in the United States frequently contain many referenda as well as partisan races for offices from the national level down to the most local, and as many as ten parties compete in many races.

It is straightforward to hand count ballots with only one race on the ballot and only a few candidates. A typical methodology is to sort the ballots into piles by candidate and then count the pieces of paper in each pile. Such a count is fairly easy to observe and check. In contrast, there is no simple method to quickly and accurately hand count complex general election ballots.

A key to the survival of paper ballots was the development of the Australian system of secret balloting. In this system, ballots listing all qualified candidates are printed at government expense. Ballots are then distributed to voters at polling places, where voters mark their ballots in the privacy of voting booths.

The Australian state of Victoria adopted this idea in 1856 [3], but its spread outside of Australia was slow. The British adopted this system in 1872 [4]. By 1892, the same year that mechanical voting machines saw their first use in the United States, the Australian model was in use in over 80 percent of the United States [18].

While the Australian secret ballot requires no technology more advanced than the printing press, as suggested by Figure 1, it is a sophisticated invention. The sophistication is procedural, not technological. There are specific procedural countermeasures to each of many threats to the integrity of an Australian secret ballot election. Many of these defensive measures have been known for decades [29]. Typical threats and defensive measures are summarized in the following paragraphs:

Ballot box stuffing, that is, the addition of pre-voted ballots to the ballot box, usually by corrupt election officials. To defend against this, the number of pollbook signatures should be compared with the number of ballots in the ballot box at the close of the polls. Ideally, there should be incident reports explaining any discrepancies, such as voters who fled after signing the pollbook without voting. All of these records should be public, so that the existence of problems is exposed. 


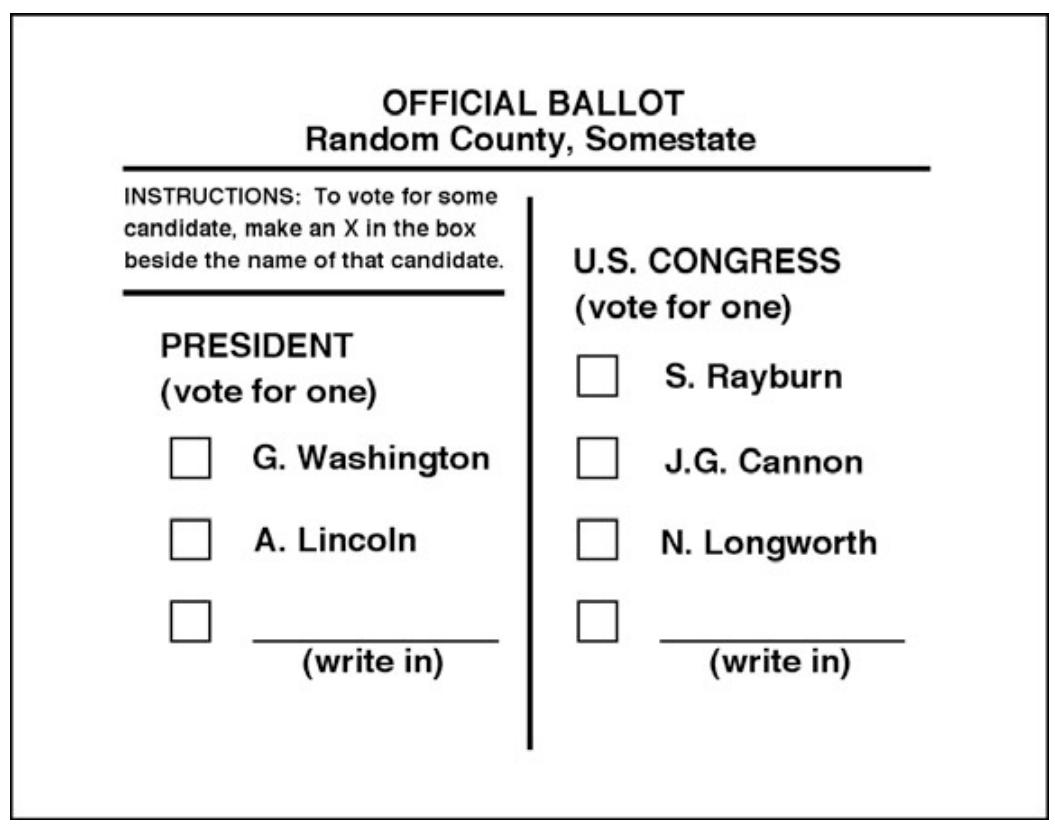

Fig. 1. An Australian secret ballot, that is, a ballot with the names of all qualified candidates printed on it. This example is for a fictional and greatly simplified general election with two different races on the ballot.

Ballot box substitution and Pollbook alteration allow the above check to be defeated. To prevent this, all processes should be open to public observation and where this is difficult, all materials should be in the joint custody of mutually distrustful adversaries such as members of opposing parties. Complete records of the chain of custody need to be maintained for all critical materials, and these should be public.

Ballot alteration during the count has been reported in some elections. No pens, pencils or erasers should be allowed within reach of the tellers who handle ballots, and tellers should wear white gloves or accept manicures from adversaries. This latter measure prevents hiding bits of pencil lead under fingernails.

Clerical Errors can corrupt the count, and where small errors are common, election manipulation can be disguised as error. To prevent errors in the count, tellers should sort ballots by how they are marked and then count the number of ballots in each pile. This procedure is comparable to the way large quantities of money are usually counted. As with money, counting does not alter what is being counted, so in the event of any controversy about the count, the process can be repeated.

Biased Counting is possible. For example, tellers can strictly apply the law on proper ballot markings for ballots they disapprove of, while generously interpreting voter intent for ballots they like. To defend against this, tellers should work in pairs made of representatives of opposing parties. While sorting ballots, they should sort disputed ballots separately from ballots they agree on. Disputed ballots should be further segregated by the nature of the dispute. The official 
record of the count should then include the number of ballots in each disputed category. The purpose of this is to expose the existence of bias and the frequency with which voters mark ballots in ways subject to dispute. In the event of any controversy, the entire count can be redone.

Chain Voting is the most sophisticated fraud technique that has been employed against Australian ballot elections; it has been well documented for well over half a century [29] (see pages pages 40, 298, 299 and 373). The organizer of the chain needs one valid ballot to begin with. He then marks this ballot and gives it to a voter willing to participate in the fraud. With each participant, the organizer instructs the participant to vote the pre-voted ballot and bring back a blank ballot from the polling place. Voters are paid for the blank ballot. The best defense against chain voting involves printing a unique serial number on a removable stub on each ballot. When ballots are issued to voters, the stub numbers should be recorded. No ballot should be accepted for deposit in the ballot box unless its stub number matches a recently issued number. Finally, to preserve the voter's right to a secret ballot, the stub should be torn from the ballot before it is inserted in the ballot box.

Punched card ballots and optical mark-sense ballots are simple variations on the Australian secret ballot. All of the procedural defenses of the Australian method apply to these new technologies, and automated ballot counting addresses the single most challenging feature of the Australian model when applied to an American general election, the presence of many tens of different races on each ballot. Placement of multiple races on one ballot makes manual counting both error prone and time consuming. It is so time consuming that observers rarely stay through the entire process.

\section{Mark-Sense Ballots}

Practical mark-sense scanners were first developed for educational testing, but by 1953, proposals for mark-sense ballots were being advanced [36]. The Norden Electronic Vote Tallying System was the first system to apply optical mark sensing to ballots [44] [20] (see pages 25-27 and 55). Both of these early systems required the use of special inks, but the Votronic, patented in 1965, sensed ordinary pencil marks [31] [38] (see page 27).

On these ballots and their successors, preprinted voting targets, indicate where the voter is to mark the ballot. Scanners developed between the 1960s and the 1990s required that all voting targets be aligned in vertical tracks, one per sensor assembly on the scanner. One or more additional tracks of index marks define the positions of the voting targets along each track. Finally, it is common to include an index mark at the top and bottom of each track in order to test for faulty sensors and check for any skew in feeding the ballot through the scanner. Figure 2 illustrates such a ballot layout.

While most mark-sense ballots use oval or elliptical targets, with the index marks on opposite edges of the ballot, there are alternatives. The Optech line of scanners, for example, use a broken-arrow as a target, instructing voters to 


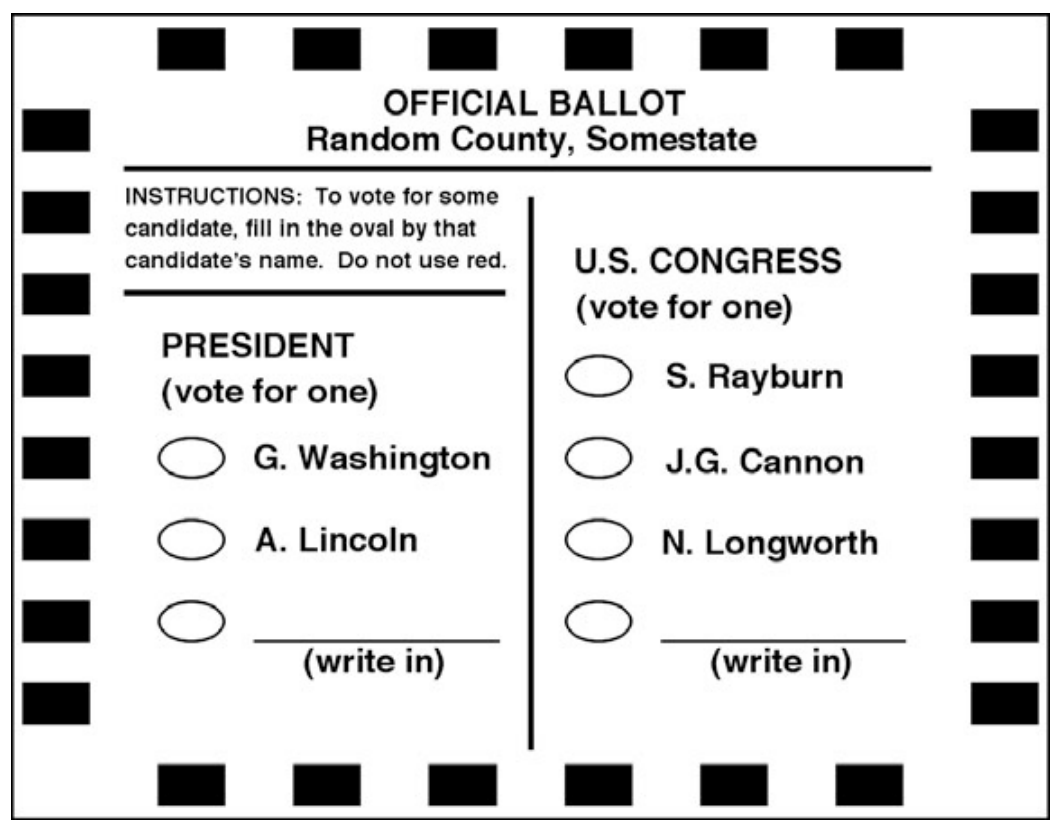

Fig. 2. A mark-sense version of the ballot from Figure 1. Index marks have been added around the edges to allow the scanner to locate the voting targets, the form of the targets has been changed, and the instructions have been changed to match the requirements of the scanner.

connect the two halves of the arrow in order to cast a vote. The two halves of the arrow in this system are used as index marks to locate the target area between them [39].

It is important to note that the sensitive area of the ballot, where marks will be sensed as votes, need not be the same as the area outlined by the voting target. Rather, the sensitive area is defined by the geometry of the sensor itself and the positions of the index marks. The ballot shown in Figure 2, for example, has index marks defining 8 rows and 6 columns, for a total of 48 sensitive areas. Of these, only 7 have an assigned meaning on this ballot.

\section{What Is a Vote?}

The instructions for marking a ballot prescribe some mark, for example, filling in the oval voting target or connecting the two halves of a broken arrow voting target. This prescribed mark is designed to be reliably counted by the sensor system and easily explained to voters. When the voting target is an oval or ellipse, as shown in Figure 2, the prescribed mark is generally a perfectly filled oval, as shown in Figure 3a.

The universe of all possible markings of a particular sensitive area on a ballot can be classified as either legal votes if the law accepts them as indicating votes 


\section{G. Washington}

(a) The prescribed mark that voters are instructed to make.

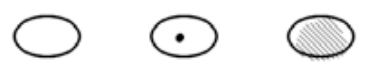

(c) Reliably ignored marks that never count as votes, including (center) an accidental hesitation mark and a smudge.

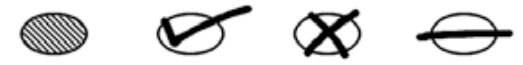

(b) Reliably sensed marks that always count as votes.

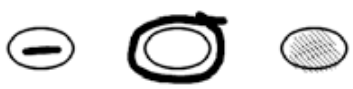

(d) Marginal marks that may or may not be counted as votes from one pass through the scanner to the next.

Fig. 3. Classes of ballot markings, distinguished by how they are recognized by a typical optical mark-sense ballot scanner. Illustration based on results for the Election Systems and Software model 650 scanner, as reported in [33].

and legally ignored if the law considers them not to be votes. In addition, independently of whether the mark is or is not considered a vote by the law, it may be classified according to how the scanner interprets it.

Marks may be reliably sensed, if every time that mark is seen by a properly adjusted scanner, it is always counted as a vote. In general, the scanners the author has tested reliably sense a variety of marks. The results in Figure 3b are typical. In general, attempts to duplicate the prescribed mark using pencil are reliably sensed, regardless of what kind of marker is prescribed. In addition, checks, X marks and single pen strokes made with the marker originally prescribed by the developer of the voting system are reliably sensed. Some scanners exhibit considerable variation in sensitivity [34] (see Exhibits 5 to 7).

A mark is reliably ignored if it is never seen by the scanner. Of course, an unmarked voting target should be reliably ignored, but so should flecks in the paper, smudges and hesitation marks, as suggested in Figure 3c. Hesitation marks are a fairly common artifact found on mark-sense forms. They are the result of people using the marker as a pointer to point to targets as they consider whether to mark those targets.

Finally, there are invariably some marginal marks. These are marks that may or may not be sensed, depending on when they are run through the voting machine and which particular sensor the mark happens to be seen by. Dark smudges, short lines within the voting target and marks entirely outside but close to the voting target are frequently marginal. Attempts by voters to imitate the prescribed mark using red ink are particularly problematic on scanners that use red or infrared light to illuminate the page.

Obviously, the prescribed mark should be both a legal vote and reliably sensed, as should all approximations of the prescribed mark likely to be made by voters. Similarly, smudges and similar accidental markings should be both legally ignored and reliably ignored.

There is a three-way interaction here between the voting system, the law and the voters. Unfortunately, there is no consensus about how the set of markings 
on a ballot should be legally classified. The most dangerous approach is known as the machine model. This defines as legal votes whatever the machine accepts [14]. The machine model does not allow for the existence of marginal marks, nor does it provide any criteria for judging whether the scanners conform to the law.

At the other extreme are laws that enumerate the types of markings that are legal votes. Consider, for example, Michigan's rules as of 2004 [9]. These rules, and the law on which they are based, do not distinguish between the sensitive area and the voting target. They declare some markings to be legal votes that a scanner may miss, while declaring other marks to be legally ignored even though a scanner might count them, as illustrated in Figure 4.

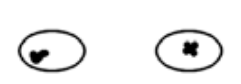

(a) Legal votes that are not reliably sensed because the marks are small but deliberately made.

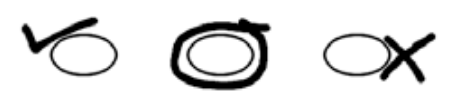

(b) Marks that may be sensed that are not legal votes because they are outside the target.

Fig. 4. Problematic ballot markings under Michigan law if scanned on the Election Systems and Software model 650 scanner. Illustration combines results from [33] with the law in [9].

These discrepancies between legal votes and what the scanner counts are troublesome, but they are not necessarily a major problem. So long as real voters rarely make these marks, they can be ignored except in very close races, and when there is such a race, hand recounts can be used to resolve them. It is, however, important to know what fraction of ballot markings are problematic. Without knowing this, we cannot evaluate human factors problems with the ballots, nor can we determine when to call for a hand recount.

\section{$5 \quad$ Scanning Technology}

The first generation of mark-sense scanners employed a single sensing element per vertical track down the ballot, as illustrated in Figure 5. The Votronic system, employing this sensor, saw widespread use from 1964 into the 1970s [20] (see pages $2756,59-60$ and 62). While the Votronic sensor employed an ordinary light bulb to illuminate the ballot, the silicon photosensor had its peak sensitivity in the infrared.

Infrared photosensors remain in use to this day. The advantage of such sensors is that they allow voting targets to be printed red ink or some other ink invisible to the photosensor, thus simplifying sensor calibration. The disadvantage of this is that voters are ill equipped to judge whether the marks they have made are reflective at infrared wavelengths.

The disadvantages of infrared scanning are clearly documented in the Optech $4 \mathrm{C}$ patent, where it is noted that "most common pens do not use ink that adsorbs infra-red light" [43]. This is particularly troublesome with postal ballots 


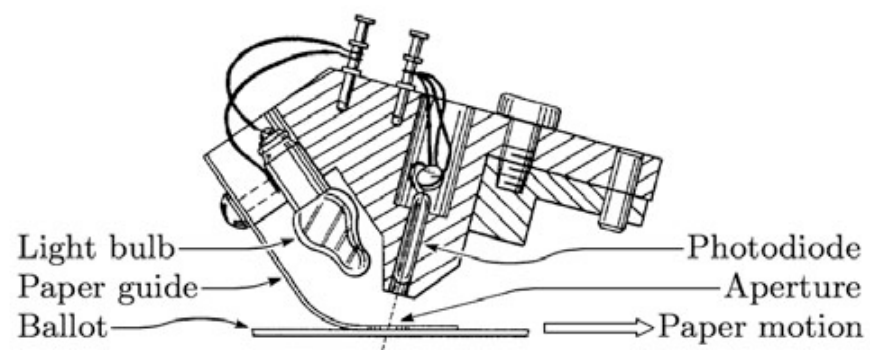

Fig. 5. Section through the Votronic optical mark-sensing assembly along the direction of paper motion, based on [31]

because it is difficult to control what kind of ballot markers are used outside the controlled context of the voting booth.

While it is easy to imagine the sensitive area of the ballot having sharp edges, most scanners using discrete sensors have relatively broad scanning tracks and are more sensitive toward the center of the track than the edges. This is a natural result of scanning through a circular aperture or an aperture with circular corners, as illustrated in Figure 5. When the scanner does not physically contact the ballot, for example, to avoid smudging any marks that might be present, the edge of the sensitive area is not sharply defined.

In the direction along the scanning track, the boundary of the sensitive area is defined by the temporal response of the scanning circuitry and by how the analog signal from the sensor is sampled. In order to avoid sensing smudges, for example, scanners can be designed to check not only the intensity signal but the derivative of that signal, so that a faint mark with sharp edges is counted even while a darker smudge is ignored.

Any systems that use paper must account for the fact that paper is not dimensionally stable. Paper expands with increasing humidity, with dimensional changes approaching one percent [27]. The placement of index marks along the long dimension of the page allows the scanner to automatically compensate for changes in that dimension, and the use of voting targets and scanning tracks that are wide along the short dimension of the page allows dimensional changes along that dimension to be largely ignored.

The development of mass produced fax machines and page scanners allowed more than one sensing element to be positioned over each track of the ballot. With this change, mark-sensing shifts from the domain of signal processing to the domain of image processing. The American Information Systems Model 100 Precinct Ballot Scanner was one of the first to employ imaging technology [1]. Although this fact and the pixel-counting threshold algorithm it used to distinguish between different types of ballot markings can be inferred from manuals dating to 1997, public disclosure of these algorithms only occurred in the patent issued in 2005 [22].

The emphasis in the design of the AIS Model 100 was on scanning ballot formats originally developed for discrete-sensor scanners. These ballots included a complete suite of index marks, with additional marks allowing the scanner to 


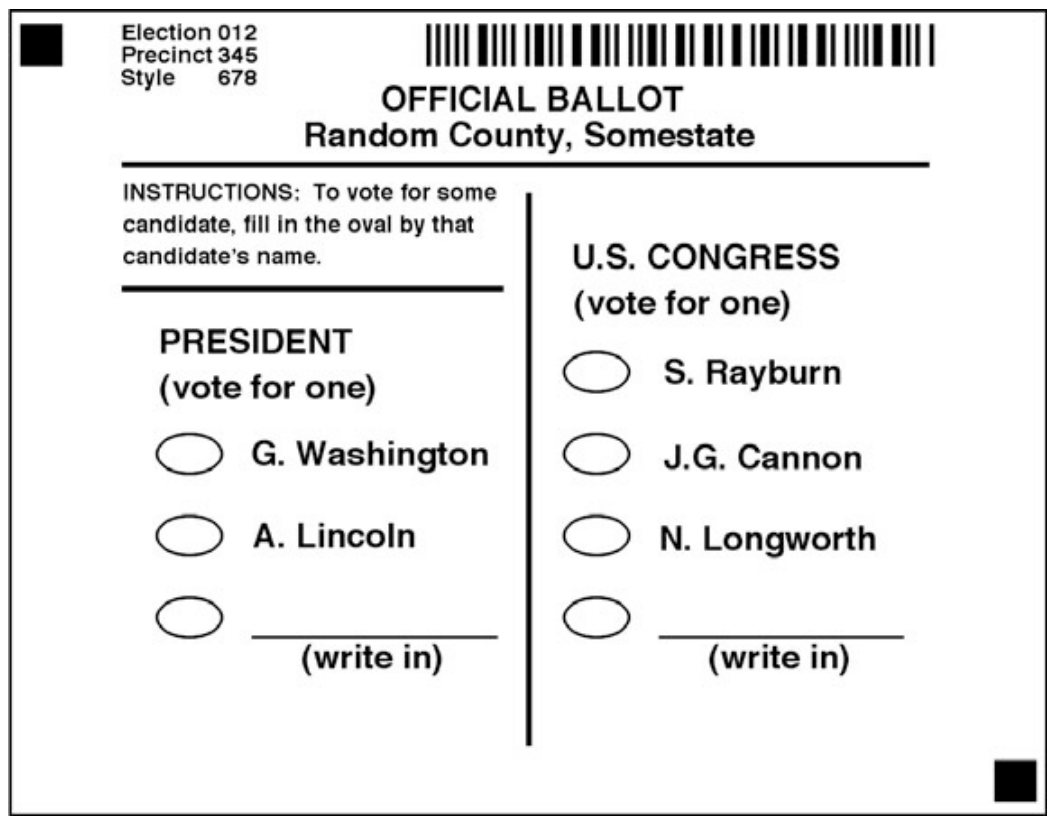

Fig. 6. A ballot based on those in Figures 1 and 2 designed for scanning using imaging technology. Two fiducial marks in opposite corners allow the analysis software to interpolate the voting target locations. A bar code allows the software to distinguish between different ballot styles that might be used. The form shown here is based loosely on that used by the Fidlar and Chambers AbScan-T [5].

detect the ballot orientation. In addition, one scanning track is used as what is essentially a long low-density bar code to encode precinct-number and ballot style. Another voting system vendor, Fidlar and Chambers, was not constrained by compatibility with the past.

The Fidlar and Chambers AbScan-T absentee ballot system came to market in early 2000 [13]. This system used a commercial off-the-shelf flatbed scanner and page feeder to scan ballots for processing on a personal computer [7]. The ballot layout used on this machine is illustrated, in reduced scale, in Figure 6 .

The Fidlar ballot included two obvious changes from earlier mark-sense ballots. First, it incorporated a conventional looking bar code where earlier scanners had used code tracks or code regions that a naive observer might not recognize as a bar code. Second, instead of index marks around the edges of the ballot, it had just two fiducial marks on opposite corners of the ballot. The term fiducial mark comes from the field of photogrammetry; it refers to a mark used as a point of reference for locating or measuring the locations of features in an image. Having located these marks, the ballot analysis software can use them to identify the ballot scale and orientation before searching for the bar code and voting targets.

Scanners such as the AIS Model 100 rely on technology originally developed for fax machines to see the ballot in black-and-white, with no shades of grey. At most, such scanners allow the overall black-white threshold to be set once, before the capture of a ballot image for processing. Image scanners offer the potential 
to dynamically adapt to the background color of the page and judge the presence of markings on the ballot on the basis of criteria more sophisticated than merely counting the black pixels within some predefined sensitive area around each voting target.

To date, commercial mark-sense ballot scanners generally recognize marks by counting the number of dark pixels in the sensitive area enclosing each voting target. This approach reappears, for example, in the claims of a patent issued in 2006 [24]. An experimental ballot tabulator has been demonstrated that uses a significantly more sophisticated mark-recognition algorithm. It first analyzes the image of the ballot using an edge detection algorithm, and then locates closed rings of edges in the image. Unmarked voting targets appear as pairs of concentric rings, while completely filled targets appear as single rings. With this algorithm, the targets themselves can serve as fiducial marks, allowing easy recovery of data from ballots images even if they are significantly distorted. Reliance on edge detection eliminates sensitivity to the background illumination level. The initial demonstration of this algorithm used a video camera to read the ballots from a distance using ambient lighting and and off-axis viewing [19].

There is clearly room for considerable elaboration on the use of edge detection in ballot image analysis. Consider the problem of dealing with non-standard but legal marks such as were illustrated in Figure 3b; a simple search for closed rings in the image will not count these as votes.

\section{Second Chance Voting}

With the advent of microprocessors, scanners became inexpensive enough that it was practical to install one ballot tabulator in each precinct, integrated into the ballot box. The Gyrex MTB-1, introduced in the mid 1970s, was an important early example of such a machine [40] [38] (see page 42). This used a very primitive bar code to encode ballot style, thus allowing the use of multiple ballot styles in one precinct, as is required for partisan primary elections, and it incorporated a printer so that it could print results immediately when the polls were closed. In combination, these features address an important category of threat:

Ballot alteration or ballot substitution: Immediate scanning eliminates the opportunity to alter ballots or substitute alternate ballots between the time they are voted and the time they are counted. In effect, from the moment the ballots are scanned onward, there are two independent records of the vote, one on the marked paper ballot itself, and one in the scanner's memory. Of course, problems will be detected only if the paper ballots in the ballot box are actually examined. In 1965, California enacted legislation requiring such an examination in randomly selected precincts after every election; more recently, several other states have enacted such legislation [8].

A second feature of precinct-count equipment emerged later, the ability to return ballots to the voter. This emerged with the CESI Optech I scanner [28] [20] (see pages 67-68). While this may have originated as a way to clear jams and handle misread ballots, it quickly emerged that one of the most valuable 
features of precinct-count scanners was that they could reject overvoted ballots, returning them to the voter. Direct recording mechanical and electronic voting machines have routinely offered this protection since the 19th century [42]. With the passage of the Help America Vote Act of 2002 (HAVA), all voting equipment used at polling places in the United States is required to offer this protection [6].

Most precinct-count scanners in current use can also return ballots that scan as blank. This offers protection for voters who use ballot markers invisible to the scanner, and it offers protection for those who completely misunderstand the ballot marking instructions by marking entirely outside the sensitive areas on the ballot. Generally, when ballots contain multiple races, as in general elections in the United States, it has not proven to be useful to return ballots where votes are found in some races but not in others. In such elections, most voters abstain some races.

When ballots are centrally counted, for example, where postal voting is used, voters have no equivalent protection against overvoting. HAVA suggests that voter education and instructions can substitute for this, but there is ample evidence that this is not true. The best current practice for postal voting is to require that the ballot scanner sort out all ballots that scan as blank or contain overvotes. These ballots should then be examined by the canvassing board to determine if they contain indications of voter intent. Typically, in general elections in the United States, the canvassing board must examine around 4 percent of the ballots [21].

Imaging scanners allow an alternative approach to resolving questionable markings on centrally counted ballots. Instead of sorting out the ballots requiring human inspection, the vote tabulation system can present scanned images of these ballots to the canvassing board for resolution. This was done in the 2007 Scottish Parliamentary elections [10], and the same functionality is present in the Ballot Now system from Hart Intercivic [2]. When the actual ballot is not examined to resolve the markings on the ballot, it is within reason to ask that any audit of the election inspect the authenticity of the ballot images that were examined as well as how each problematic marking was resolved.

\section{Human Factors}

All voting systems, from the most primitive to the most technological, are datacapture systems. This is true whether we ask voters to enter their selection directly into computers, to mark their selections on paper for manual processing, or to mark their selections on paper for scanning by a vote tabulating machine.

The single greatest strength of mark-sense voting is that the basic medium, pen or pencil marks on paper, is one with which the vast majority of voters are expert. Most people began their formal training in the use of this medium in kindergarten, and it is fair to say that the average person has far more training and experience with making and interpreting marks on paper than with any other data recording medium.

Despite this familiarity, there is ample evidence that very small changes in voter instructions can lead to significant changes in the likelihood that voters 
will correctly express their intent [33]. For example, the instructions on the ballot used in Maricopa County, Arizona, on September 7, 2004 said "TO VOTE: Complete the arrow(s) pointing to your choice with a single line," with appropriate illustrations. When the ballot tabulating system was tested, it was found that a single line made with a common ballpoint pen was a marginal mark [34] (see Exhibit 8). Fortunately, most voters scrupulously darken their marks, but the instruction to make a single line may have mislead an unknown number of voters.

The author suggests that a voting target be printed in the pollbook next to the name of each eligible voter. On signing the pollbook, the voter could then be asked to properly mark this oval. Doing this would give pollworkers an opportunity to observe any difficulty people have making an appropriate mark in a context where there is no threat to the voter's right to a secret ballot.

The 1990 and 2002 federal voting system standards required that mark-sense scanners distinguish between the prescribed mark, on the one hand, and smudges or creases, on the other. They did not, however, require any exploration of the universe of other markings voters might make [12] [17]. Unfortunately, while the 2005 guidelines incorporated an extensive human-factors section, this is focused largely on handicapped accessibility and it does not alter the requirements for mark-sense tabulation accuracy [15].

It is noteworthy that post election auditing of mark-sense ballot tabulation systems can do more than audit the correctness of the count. A properly conducted post-election audit of mark-sense ballots should also note the number of ballots marked with nonstandard markings. In contrast, the audits proposed for direct-recording electronic voting systems tend to focus exclusively on the count and exclude human-factors issues [32].

\section{Disability Problems}

Mark-sense ballots do pose some difficult challenges. In jurisdictions requiring multilingual ballots, adding an extra language to each ballot adds clutter, and this decreases readability. This is tolerable with bilingual ballots, but where three or more languages are required, readability declines rapidly.

A more serious problem involves access for voters with disabilities, particularly blind voters, but also those with motor disabilities and poor eyesight. Voters who need large print can be aided by providing them with magnifying glasses. While these are somewhat cumbersome, they are also a very familiar technology. Similarly, voters with motor disabilities can be provided with transparent ballot overlays to protect the ballot from stray marks and scribbles. These measures meet the needs of the majority of voters who might otherwise need assistance in casting their votes, but they are rarely provided in modern polling places.

Since the passage of the Help America Vote Act of 2002 in the United States, the problem of providing access to the blind has frequently solved by providing one handicapped accessible voting system per polling place. In many jurisdictions, a direct-recording electronic voting machine is used for this purpose. Use 
of multiple vote recording systems threatens voter privacy, particularly if only a few voters use the accessible system while the majority use mark-sense ballots.

Voter privacy is improved if the ballots voted by blind voters or others needing assistance are merged with all other ballots voted at the same location prior to tabulation. This idea has lead to the development of several accessible ballot marking devices that allow blind voters to mark paper ballots. The AutoMark [25] and the Vote-PAD [11] are the two most widely discussed. These devices seek to achieve the same goal, but they do so in radically different ways.

The AutoMark uses any of several input devices to capture the voter's choice, and then it uses ink-jet printer technology to record that choice on a standard mark-sense ballot. The input devices are typical of direct-recording electronic voting machines, enough so that this machine could be classified as an indirectrecording electronic voting machine.

In contrast, the Vote-PAD is a tactile ballot [26]. That is, it is a template that fits over the ballot, allowing the voter to mark the ballot through holes in the template. This alone is sufficient to aid most sighted voters with motor disabilities. For those who cannot read the ballot, a recorded script is provided to narrate the ballot.

Tactile ballots have been used with great success in many countries, but in most of these cases, elections typically involve a single race with only a few candidates. When used for a general election in the United States, the audio narration of the ballot can easily take 15 minutes, and audio instruction for how to navigate a large ballot is both cumbersome and error prone.

There is clearly room to explore other solutions to making mark-sense ballots more accessible. One proposal combines the mechanics of a tactile ballot with the mechanism of a graphics tablet. With this system, instead of following an audio script, the voter is free to explore the ballot by moving a sensing wand over the template. The system senses the location of the wand and reads whatever ballot position the voter selects, reporting on whether or not it has already been voted. While such a mechanism might cost considerably more than a tactile ballot, it would be considerably less expensive than an AutoMark machine [35].

\section{Conclusion}

Optical mark-sense vote tabulation will remain widely used into the indefinite future. It is the only technology for automatic vote tabulation that is applicable to postal voting, and there are promising technologies available to permit disabled voters to use mark-sense ballots at polling places. From a security perspective, it can be judged highly secure if appropriate post election audit procedures are used.

As such, optical mark-sense systems are one of the best voting technologies available for complex general elections. There are, however, several areas where additional work needs to be done. First among these is the development of assistive technologies that are both inexpensive and effective for complex general elections. 
A second frontier lies at the heart of the mark-sensing mechanism itself. Marksensing algorithms that make intelligent decisions based on image analysis are currently in their infancy. Only the most tentative experiments have been made with applying image processing techniques to this area.

As with all voting technologies, there are major problems with the diffusion of best practices. Some jurisdictions have long employed sound practices for post-election audits, processing of overvoted ballots, and wording of ballot instructions, while these same practices remain essentially unknown in other jurisdictions. Voting system standards, state oversight and further professionalization of voting system administrators will all play a role in solving this problem.

\section{References}

1. AIS Model 100 Precinct Ballot Scanner Operator's Manual, Version Release 2.1, American Information Systems (August 1997)

2. Ballot Now Intelligent Ballot Management, Hart InterCivic (2005)

3. The Electoral Act of 1856, Victoria, Australia (1856)

4. Procedures at a General Election, British Department for Constitutional Affairs, August 17, 2001. Paragraphs 11.14 through 11.18 (2001)

5. Official Ballot General Election, Clay County Iowa, November 7 (2000)

6. The Help America Vote Act of 2002, Public Law 107-252, 107th Congress, Title III, Sec 301(a)1(A) (2002)

7. Minutes of Examination and Test, Board of Examiners for Voting Machines and Electronic Voting Systems, Iowa Secretary of State, October 17 (2000)

8. Manual Audit Requirements, Verified Voting Foundation, November 1 (2006)

9. Determining the Validity of Optical Scan Ballot Markings, State of Michigan Department of State, July 18 (2006)

10. Managing the Scottish Parliamentary and local government elections guidance for Returning Officers, UK Electoral Commission, Section F, 3, pp. 181-186 (2007)

11. Vote-PAD (Voting-on-Paper Assistive Device) - Independent Voting for People with Disabilities, Vote-PAD Inc. (2007)

12. Performance and Test Standards for Punchcard, Marksense, and Direct Recording Electronic Voting Systems, Federal Election Commission, Section 3.2.5.2.1 (Janaury 1990)

13. Contract between Fidlar \& Chambers Co. and the Surry County Board of Commissioners, Surry County, North Carolina, Janaury 26 (2000)

14. U.S. Court of Appeals, 11th Circuit, December 6, 2000, Touchston and Shepperd vs. Michael McDermott, No. 00-15985 (2000)

15. Voluntary Voting System Guidelines, U.S. Election Assistance Commission (2005)

16. Voting Machines, Encyclopaedia Britannica, 11th edn., vol. 28 (1910)

17. Voting System Performance and Test Standards, Federal Election Commission, vol. I, Section 3.2.4.2.3 (2002)

18. Ackerman, S.J.: The Vote that Failed, Smithsonian (November 1998)

19. Adi, A., Adi, W.: Demonstration of Open Counting: A Paper-Assisted Voting System with Public OMR-At-A-Distance Counting. In: VoComp 2007, Portland, Oregon, July 17 (2007) 
20. Arnold, E.G.: History of Voting Systems in California, California Secretary of State Bill Jones (June 1999)

21. Berghoefer, F.: Transcript of oral testimony, Technical Guidelines Development Committee Public Data Gathering Hearings, September 20 (2004)

22. Bolton, S., Cordes, T., Deutsch, H.: Method of Analyzing Marks Made on a Response Sheet, U.S., February 15 (2005) Patent 6,854,644

23. Brace, K.W.: Overview of Voting Equipment Usage in United States, Direct Recording Electronic (DRE) Voting, statement to the United States Election Assistance Commission, May 5 (2004)

24. Chung, K.K., Dong, V.J., Shi, X.: Electronic Voting Method for Optically Scanned Ballot, U.S., July 18 (2006) Patent 7,077,313

25. Cummings, E.M.: Ballot Marking System and Apparatus, U.S., July 25 (2006) Patent 7,080,779

26. Davidson, A., Ricks, S.: Tactile Ballot for the Visually Impaired of Marion County, Oregon, Appendix C of Independent, Secret and Verifiable - A guide to Making Voting an Independent and Accessible Process for People who are Blind and Visually Impaired, American Council for the Blind (September 2002)

27. Dwan, A.: Paper Complexity and the Interpretation of Conservation Research. Journal of the American Institute for Conservation 26(1), 1-17 (1987)

28. Charles Fogg, M., Krieger, C.F., Veale, J.R.: System and Method for Reading Marks on a Document, U.S., October 23 (1984) Patent 4,479,194

29. Harris, J.P.: Election Administration in the United States. The Brookings Institution (1934)

30. Harris, J.P.: Data Registering Device, U.S., August 17 (1965) Patents 3,201,038, March 15 (1966) 3,240,409

31. Holzer, G., Walker, N., Wilcock, H.: Vote Tallying Machine, U.S., November 16 (1965) Patent 3,218,439

32. Jones, D.W.: Auditing Elections. Comm. ACM 47(10), 46-50 (2004)

33. Jones, D.W.: Observations and Recommendations on Pre-election Testing in Miami-Dade County, September 9 (2004)

34. Jones, D.W.: Regarding the Optical Mark-Sense Vote Tabulators in Maricopa County, statement submitted to the Arizona Senate Government and Accountability Committee, Janaury 12 (2006)

35. Jones, D.W.: System for Handicapped Access to Voting Ballots, U.S., November 14 (2006) Patent 7,134,579

36. Keith, H.R.: Electrical Vote Counting Machine, U.S., June 12 (1956) Patent $2,750,108$

37. McKay, R.H., Ziebold, P.G., Kirby, J.D., Hetzel, D.R., Snydacker, J.U.: Electronic Voting Machine, U.S., February 19 (1974) Patent 3,793,505

38. Moloney, M.A.: Mechanized Vote Recording: A Survey, Research Report No. 116, Legislative Research Commission, Frankfort Kentucky (May 1975)

39. Narey, J.O.: Ballot for use in Automatic Tallying Apparatus and Menthod for Producing Ballot, U.S., March 21 (1989) Patent 4,813,708

40. Narey, J.O., Saylor, W.H.: Ballot Tallying System Including a Digital Programmable Read-Only Control Memory, a Digital Ballot Image Memory and a Digital Totals Memory, U.S. Patent 4,021,780

41. Saltman, R.G.: Accuracy, Integrity, and Security in Computerized Vote-Tallying, NBS Special Publication 500-158, National Bureau of Standards (August 1988) 
42. Spratt, H.W.: Improvement in Voting Apparatus, U.S., Janaury 12 (1875) Patent 158,562

43. Stewart, J.D.: Device for Optically Reading Marked Ballots using Infrared and Red Emitters, U.S., September 28 (1993) Patent 5,248,872

44. Weik, M.H.: A Third Survey of Domestic Electronic Digital Computing Systems, Ballistic Research Laboratories Report No. 1115, pp. 719-723 (March 1961)

45. Wood, F.S.: Electric Voting-Machine, U.S., December 20 (1898) Patent 616,174

46. David Zuckerman, T.: The Voting Machine. Political Research Bureau of the Republican County Committee of New York (Janaury 1925) 